\title{
Effect of simulated tennis steps and slides on tread element friction and wear
}

\author{
John Hale ${ }^{1}\left(\mathbb{D} \cdot\right.$ Roger Lewis $^{1} \cdot$ Matt J. Carré ${ }^{1}$
}

Accepted: 8 March 2021 / Published online: 23 March 2021

(c) The Author(s) 2021

\begin{abstract}
In hard court tennis, players change direction by either stepping or sliding. The shoe-surface friction during these movements is crucial to player performance. Too little friction when stepping may result in a slip. Too much friction when attempting to slide could cause the player to move only a short distance, or to fail to slide. To understand the influence of tread design on shoe-surface friction in tennis, experiments were performed on individual shoe tread elements that replicated the tribological conditions typically experienced during hard court step and slide movements. Tread element orientation had no effect on the static friction in step movements, but longer tread elements (in the sliding direction) had $9 \%$ lower dynamic friction during slide movements $(p<0.001)$. The friction between tennis shoe tread and hard court tennis surfaces is also shown to be influenced by the tread's sliding history, and the wearing pattern that forms on the surface of the rubber.
\end{abstract}

Keywords Friction $\cdot$ Shoe-surface $\cdot$ Tennis $\cdot$ Tribology

\section{Introduction}

Shoe-surface friction or traction in various sports has been linked to performance and injury risk [1-8]. Higher friction has been shown to improve the performance of change of direction movements in association football [5], basketball [3] and futsal [8]. It has also been hypothesised that higher friction during such movements increases the risk of ACL injury due to biomechanical changes often employed by athletes when performing sidesteps on higher friction surfaces, e.g. a decrease in lower knee flexion angle [9]. Understanding shoe-surface friction, and how it can be modified, is crucial to the design of effective sports footwear, especially in sports where athletes frequently change direction.

In an elite singles tennis match, a player often performs over 1000 direction change movements, with a mean of four lateral movements per point [10]. Sliding movements have

John Hale

jhale1@ sheffield.ac.uk

Roger Lewis

roger.lewis@sheffield.ac.uk

Matt J. Carré

m.j.carre@sheffield.ac.uk

1 Department of Mechanical Engineering, University of Sheffield, Sheffield S1 3JD, UK been shown to improve shot return efficiency as they allow quicker repositioning post-shot [11], as well as potentially reducing injury rates by decreasing the peak load impulses which are experienced by the player's lower extremity joints [7]. Though a common movement on clay courts, slides have also been performed by some professional players on hard courts [12]. Hard court surfaces (acrylic) are constructed from a sand-paint mixture that provides a high friction dryrough topography. As such, most changes of direction in hard court tennis are achieved through step movements.

An influential factor of any movement are the tennis shoes worn, which often vary in terms of tread pattern. Tread is typically applied to rubber components (tyres, shoes etc.) to increase friction in wet environments by channeling fluid through tread grooves [13]. Hard court tennis is played in dry conditions, yet the shoes players wear are still treaded (Fig. 1).

Studies on how shoe tread design influences friction on hard court surfaces have indicated that tread pattern and its orientation influences static $\left(\mu_{s}\right)$ and dynamic $\left(\mu_{k}\right)$ friction coefficients [14-17]. Goff et al. [14] found that $\mu_{s}$ for rectangular cuts $(3 \times 9 \mathrm{~cm})$ of rubber with different tread patterns varied by up to 0.4 at different orientations. Additionally, Ura et al. [16] observed at $700 \mathrm{~N}$ normal load, change of tennis shoe orientation increased $\mu_{k}$ by 0.2 on a hard court. As 


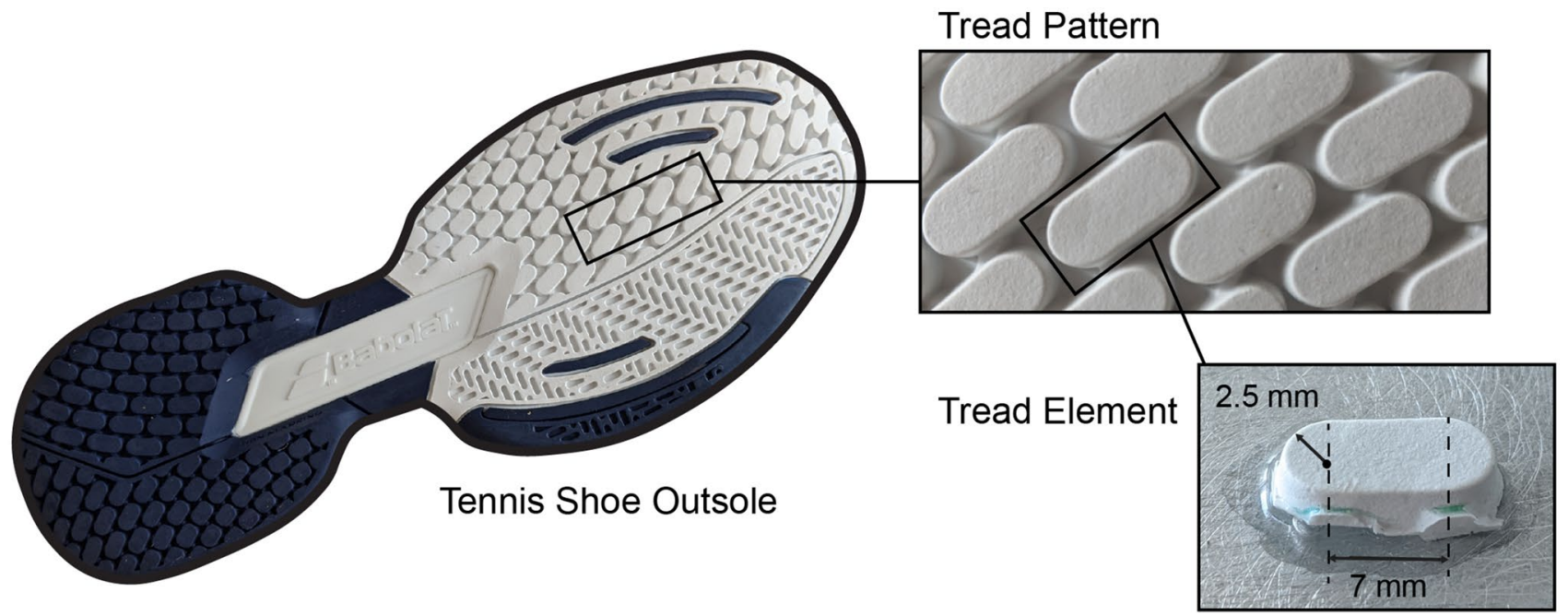

Fig. 1 An example of an outsole from a tennis shoe (Babolat Propulse Blast All Court UK 9) designed for hard court tennis. Definitions are shown of 'Tread Pattern' and a 'Tread Element'

such, changes in tread orientation clearly result in frictional differences on hard courts.

It is difficult, however, to identify from these studies the key tread parameters that cause the frictional difference. This is due to the complex nature of rubber's material properties, combined with the role of wear and frictional heating inevitable with tennis shoe surface interactions. Hale et al. [17] identified some of the frictional factors affecting tread when rubber slides on hard courts with experiments on differently shaped rubber blocks. The shortest rubber shape produced a mean $\mu_{k}$ of $0.92,0.16$ greater than that recorded for the longest rubber shape of 0.76 . From these findings, it was proposed that the shape and orientation of rubber tread elements have a frictional effect due to how they wear and heat during sliding. The tests run, however, were on idealised rubber shapes from a commercially available synthetic rubber, rather than actual tennis shoe treads. Whether the findings can be applied to real tennis shoe treads during change of direction movements is unknown.

The study of the frictional performance of individual tennis tread elements, rather than full shoes, affords the opportunity to identify friction and wear mechanisms at the tread-surface interface. This is possible due to the negation of the complexities around the inherent human variability present when testing athletes, and quantifying the energy losses caused by other interacting tread elements during mechanical full shoe tests. In previous work, a test methodology was introduced that tests the friction of individual shoe tread elements with normal forces and slide speeds replicative of steps and slides in hard court tennis [18]. The work did not determine whether tread orientation affects friction on hard court surfaces. The effects of rubber tread wear over time, and whether changes in slide direction result in differences in friction, were not previously investigated. These questions are hence addressed here, using the same methodology, with parametric statistical analysis.

It is hypothesised that tread orientation will have no effect on $\mu_{s}$ during hard court steps. Tread orientation, is however, expected to influence the $\mu_{k}$ of hard court steps and slides due to the effects of frictional heating and wearing recorded in similar interactions $[17,19,20]$. It is also hypothesised that the sliding movement will result in wear that will alter the topography of the tread elements, causing a frictional asymmetry [21]. Signs of these wearing patterns have been identified before [18], but the effect on friction has not been investigated until now.

\section{Materials and methods}

\subsection{Experiment summary}

The test method, surfaces and tread elements from [18] were used for this study. This study included more tests than [18] (30 for each condition vs 5 previously), and reverse direction tests, allowing a more comprehensive investigation into tribology at the rubber-surface interface during replicated tennis movements.

The experimental set-up shown in Fig. 2 details how the friction experiments were conducted. It also defines long and short tread orientations, and the angular speed used for the step and sliding tests. A normal load of $33 \mathrm{~N}$ was selected for step tests, and $25 \mathrm{~N}$ for the slide tests. These loads produced nominal contact pressures across the tread elements for the step $(604 \mathrm{kPa})$ and slide tests $(456 \mathrm{kPa})$, equal to those determined by mechanical shoe contact area tests, which used

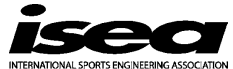



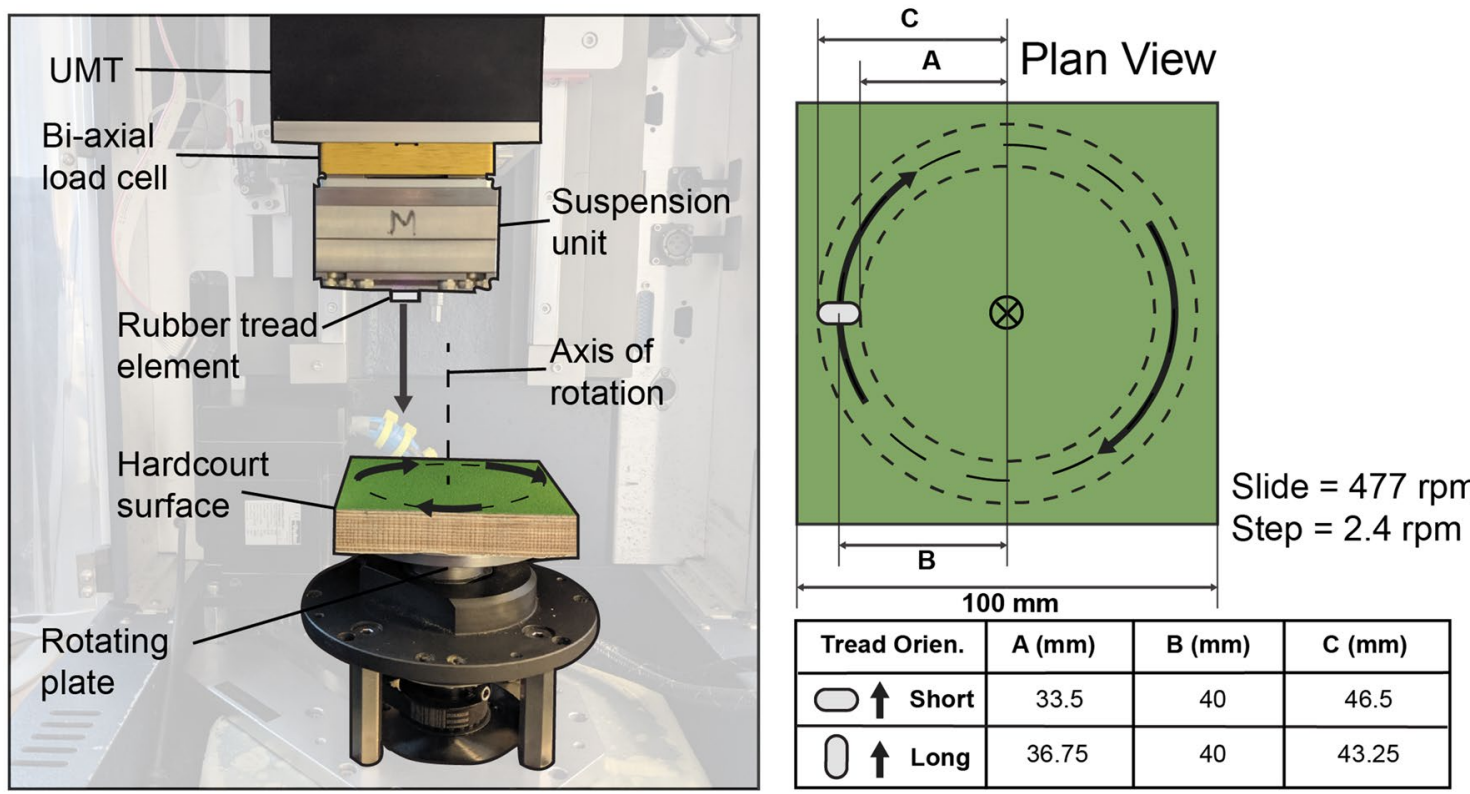

Fig. 2 Experimental set-up used. (Image taken and adapted from Ref. [18])

loads from biomechanical tests on hard court steps and slides [12, 18, 22, 23]. For example, a biomechanics study investigating hard court sliding reported normal loads between 300 and $835 \mathrm{~N}$ [12]. Selecting a load within this range (595 N), the tennis shoe from which the tread elements were cut, was loaded and the contact area quantified, giving a contact area of $1305 \mathrm{~cm}^{2}$. This resulted in a mean contact pressure across the tread of $456 \mathrm{kPa}$, which was then imitated by one tread element ( area $=54.64 \mathrm{~mm}^{2}$ ) with a normal force of $25 \mathrm{~N}$.

Table 1 summarises the four test cases. An identical tread element was used for each of the test cases. Thirty repeats were conducted for each orientation and movement. After the first 15 tests, the slide direction was reversed for another 15 tests. The surface and rubber were lightly brushed with a fine-bristled paintbrush between tests to remove any wear debris and surface contaminants. The tested tread elements are shown in Fig. 1.

Slide times were 10.0 and $0.8 \mathrm{~s}$ for the step and sliding movements, respectively, producing sliding distances of $0.1 \mathrm{~m}$ for the step tests, and $1.6 \mathrm{~m}$ for the slide tests. In elite hard court tennis, slides are shorter $(0.41-0.72 \mathrm{~m})$ and faster $(2.8-4.7 \mathrm{~m} / \mathrm{s})$ than tested here $(2 \mathrm{~m} / \mathrm{s})$ [12].
Figure 3 shows how $\mu_{s}$ and $\mu_{k}$ were determined for the step experiment, and how $\mu_{k}$ was determined for the slide experiment. Given the way in which the slide tests are conducted $\mu_{s}$ cannot be easily obtained, as there was no initial static phase, so it was omitted from this analysis. For the step experiments, $\mu_{s}$ was identified as the initial peak recorded immediately before the initiation of sliding, while $\mu_{k}$ was calculated as the mean of all $\mu$ readings for the following $7 \mathrm{~s}$ of sliding. For the sliding tests, $\mu_{k}$ was calculated as the mean of all $\mu$ readings for the first $0.5 \mathrm{~s}$ after the normal load had reached its desired value. $\mu$ values were identified as the ratio of frictional to normal force, readings obtained simultaneously from the bi-axial load cell and calculated automatically.

Mass losses of the rubber elements were taken after every five tests using an analytical balance (Satorius BasicPlus BP210D, Göttingen, Germany). Topographical analysis of the tread elements was conducted before and after testing using non-contact profilometry (Alicona InfiniteFocus SL, Optimax, Leicestershire, UK), measuring arithmetical mean surface height $\left(S_{\mathrm{a}}\right)$ and surface root mean square height $\left(S_{\mathrm{q}}\right)$.
Table 1 The key test parameters for the conducted experiments with mean (SD) of applied normal loads and slide speeds

\begin{tabular}{lllll}
\hline Experiment type & Test sample & Orientation & Normal load $(\mathrm{N})$ & Slide speed $(\mathrm{m} / \mathrm{s})$ \\
\hline Step & 1 & Short & $32.7(0.5)$ & $0.01(<0.001)$ \\
& 2 & Long & $32.7(0.3)$ & $0.01(<0.001)$ \\
Slide & 3 & Short & $22.3(2.8)$ & $2(0.011)$ \\
& 4 & Long & $22.7(3.1)$ & $2(0.012)$ \\
\hline
\end{tabular}


(a)

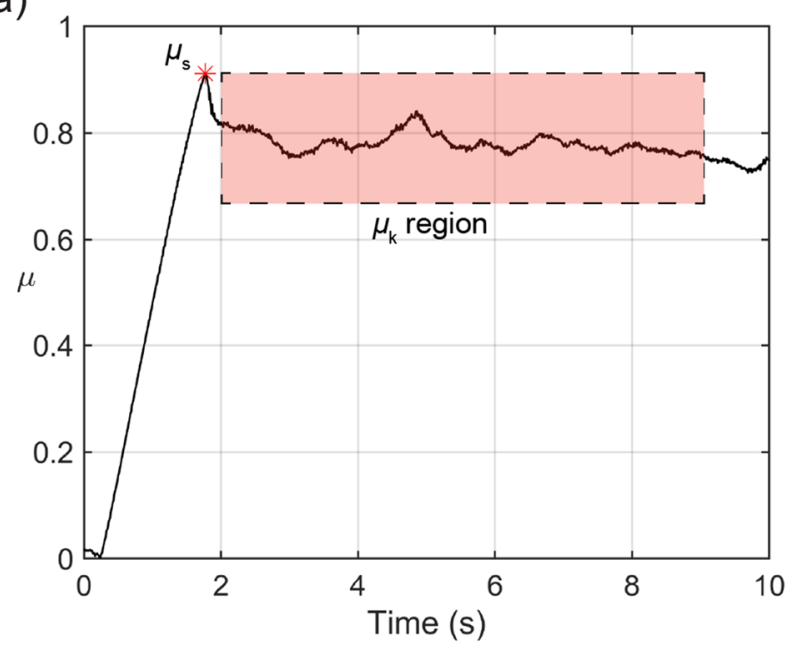

Fig. 3 a Typical $\mu$ time trace from the step experiments, the red star indicates the $\mu_{s}$ value and the red box refers to the readings from which a $\mu_{k}$ value would be calculated. b The first five $\mu$-time traces

\subsection{Statistical analysis}

Three-dependent and five independent $t$ tests with reported effect size (Hedges's $g\left(g_{s}\right)$ [24]) were used to investigate the effect of tread orientation, movement type and slide direction. Significance was assumed when $p<0.05$, and when data had been used in multiple $t$ tests, a Holm correction was applied to the significance value [25]. To calculate $g_{s}$ a pooled SD was used. As a Cohen's $d$, corrected for small sample size, $g_{s}$ values of $0.2,0.5,0.8$ relate to small, medium and large effects, respectively [26]. All statistical analysis was conducted using the IBM SPSS 26 software.

\section{Results}

Table 2 shows the mean and standard deviation (SD) for all the $\mu$ readings taken.

\subsection{Step results}

The mean (M) $\mu_{k}$ for the long and short tread orientations during the first 15 step tests were $0.77(\mathrm{SD}=0.02)$ and (b)

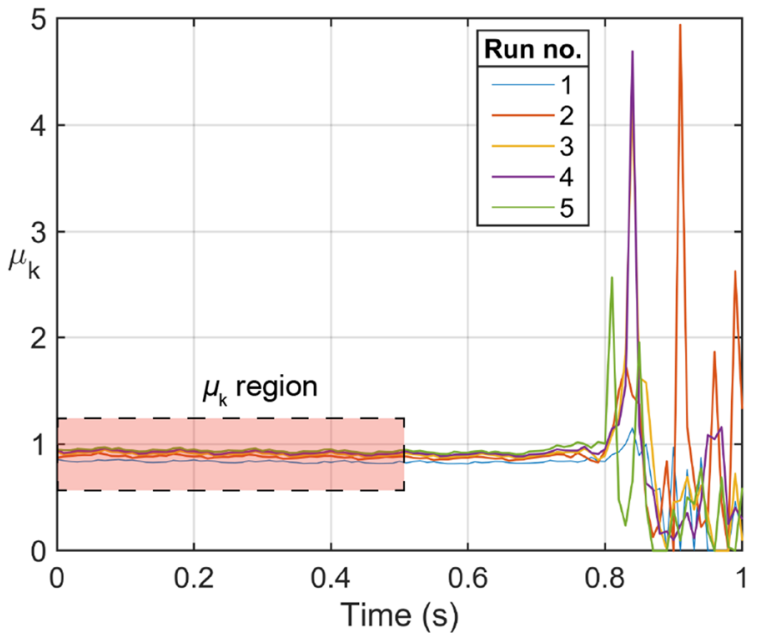

from the slide experiments on the short orientated tread, with labelled $\mu_{k}$ region (color figure online)

$0.78(\mathrm{SD}=0.01)$, respectively, with no significant difference between orientations $\left[t(28)=1.61, p=0.118, g_{s}=\right.$ $0.6]$. During the reverse 15 step tests, however, $\mu_{k}$ results for the long tread orientation $(M=0.69, \mathrm{SD}=0.01)$, were significantly higher than those for the short tread orientation $(M=0.67, \mathrm{SD}=0.01), t(28)=5.65, p<0.001, g_{s}=$ 2 . Dependent $t$ tests showed that the $\mu_{s}$ readings (for both orientations together) during the first 15 tests $(M=0.85$, $\mathrm{SD}=0.05)$, were significantly higher than those during the reverse 15 tests $(M=0.71, \mathrm{SD}=0.03), t(29)=13.22$, $p<0.001, g_{s}=3.4$. The $\mu_{k}$ readings taken from the first 15 tests $(M=0.77, \mathrm{SD}=0.01)$, were also shown to be significantly higher than those in the reverse 15 tests $(M=0.68$, $\mathrm{SD}=0.01), t(29)=29.13, p<0.001, g_{s}=9$.

Individual $\mu_{s}$ results from the step tests, with the mass loss readings taken after every five tests are shown in Fig. 4. The same is shown for $\mu_{k}$ in Fig. 5. There was little observable difference between the short and long tread orientations in terms of wear. After all 30 step tests, the short and long tread elements produced similar mass loss readings of $1.9(0.6 \%)$ and $1.8 \mathrm{mg}(0.5 \%)$, respectively.
Table 2 The mean and standard deviation, $M$ (SD), of all $\mu$ readings

\begin{tabular}{|c|c|c|c|c|c|c|c|}
\hline \multirow[t]{2}{*}{ Test } & \multirow[t]{2}{*}{ Orientation } & \multicolumn{2}{|c|}{ First 15 tests } & \multicolumn{2}{|c|}{ Reverse 15 tests } & \multicolumn{2}{|l|}{ All 30 tests } \\
\hline & & $\mu_{s}$ & $\mu_{k}$ & $\mu_{s}$ & $\mu_{k}$ & $\mu_{s}$ & $\mu_{k}$ \\
\hline \multirow[t]{2}{*}{ Step } & Short & $0.84(0.06)$ & $0.78(0.01)$ & $0.70(0.03)$ & $0.67(0.01)$ & $0.77(0.09)$ & $0.72(0.05)$ \\
\hline & Long & $0.85(0.04)$ & $0.77(0.02)$ & $0.72(0.03)$ & $0.69(0.01)$ & $0.78(0.07)$ & $0.73(0.04)$ \\
\hline \multirow[t]{2}{*}{ Slide } & Short & - & $1.03(0.06)$ & - & $0.99(0.02)$ & - & $1.01(0.05)$ \\
\hline & Long & - & $0.94(0.04)$ & - & $0.91(0.01)$ & - & $0.93(0.03)$ \\
\hline
\end{tabular}




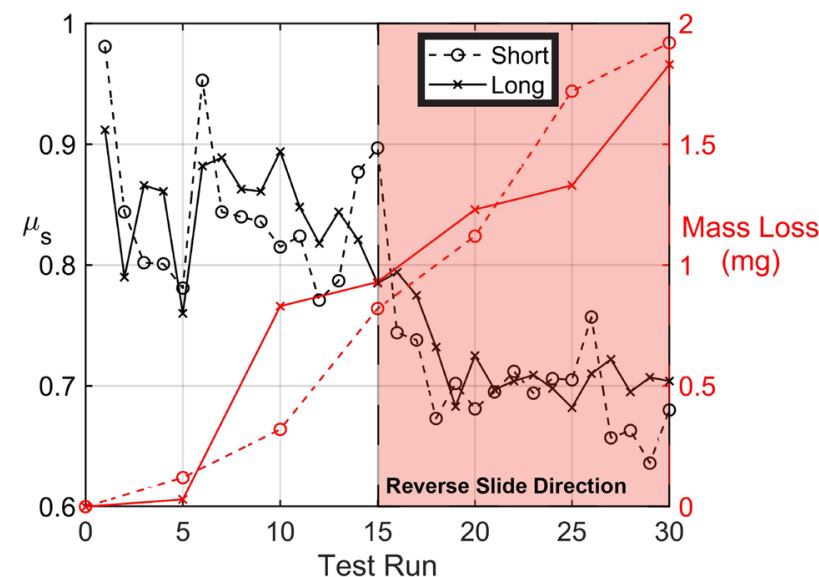

Fig. $4 \mu_{s}$ and wear graph for the step tests. The red shaded region indicates the change in slide direction after 15 runs (color figure online)

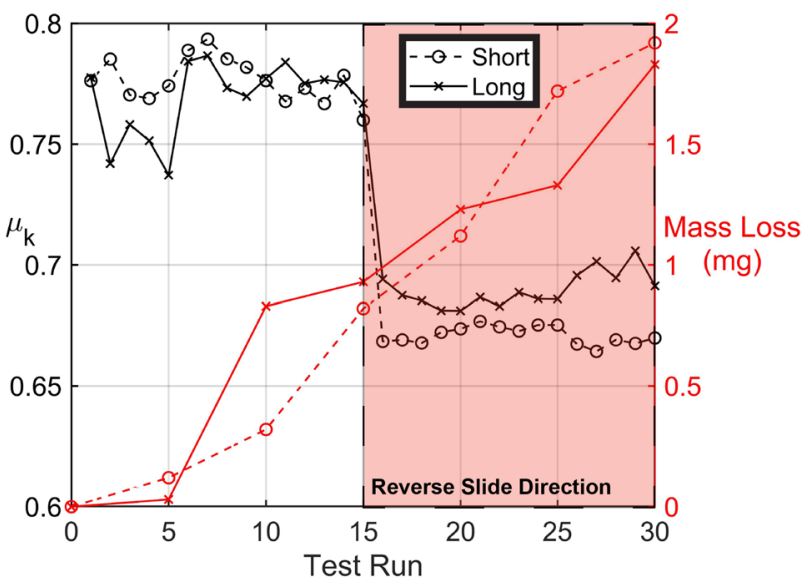

Fig. $5 \mu_{k}$ and wear graph for the step tests. The red shaded region indicates the change in slide direction after 15 runs (color figure online)

\subsection{Slide results}

The mean $\mu_{k}$ for the long and short tread orientations during the first 15 slide tests were $0.94(\mathrm{SD}=0.04)$ and 1.03 $(\mathrm{SD}=0.06)$, respectively, and were significantly different $\left[t(28)=4.72, p<0.001, g_{s}=1.8\right)$. During the reverse 15 slide tests, $\mu_{k}$ results for the long tread orientation $(M=0.91$, $\mathrm{SD}=0.01)$, were also significantly lower than those for the short tread orientation $(M=0.99, \mathrm{SD}=0.02), t(28)=15.15$, $p<0.001, g_{s}=5.1$. A dependent $t$ test determined that the $\mu_{k}$ readings (for both orientations together) during the first 15 tests $(M=0.98, \mathrm{SD}=0.07)$, where significantly higher than those during the reverse 15 tests $(M=0.95, \mathrm{SD}=0.04)$, $t(29)=3.92, p<0.001, g_{s}=0.5$.

Slide test $\mu_{k}$ readings and mass loss values are shown in Fig. 6. The short tread element had a greater total mass loss

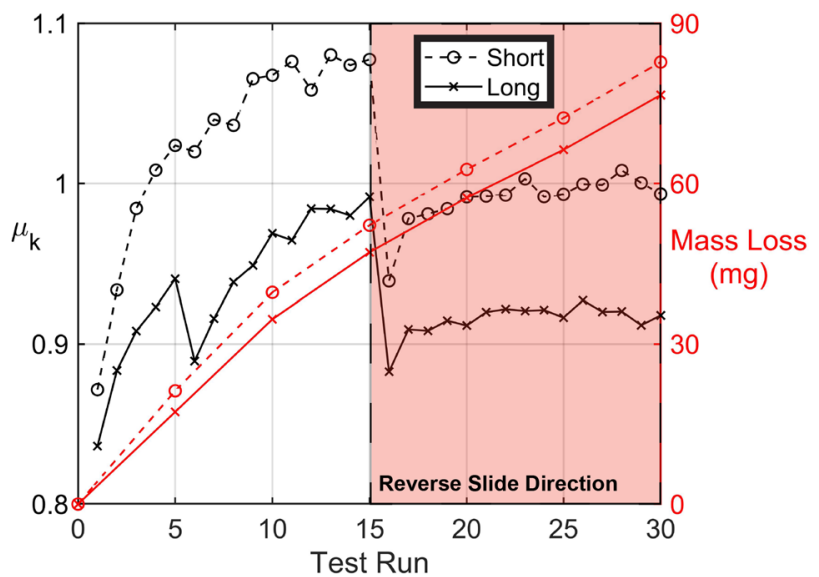

Fig. $6 \mu_{k}$ and wear graph for the slide tests. The red shaded region indicates the change in slide direction after 15 runs (color figure online)

of $83 \mathrm{mg}(25 \%)$ than $77 \mathrm{mg}$ (20\%) for the long orientated tread element. Calculating wear rate $(\delta)$ as the ratio of mass loss $(\mathrm{mg})$ to sliding distance $(\mathrm{mm})$, the tread elements used during the step tests wore at a rate of $610 \times 10^{-9} \mathrm{mg} / \mathrm{mm}$ and $640 \times 10^{-9} \mathrm{mg} / \mathrm{mm}$ for the long and short orientations, respectively. During slide tests, the long orientated tread produced a $\delta=1595 \times 10^{-9} \mathrm{mg} / \mathrm{mm}$ and the short orientated tread produced a $\delta=1724 \times 10^{-9} \mathrm{mg} / \mathrm{mm}$.

Lastly, all the $\mu_{k}$ readings from the slide experiment ( $M=0.97, \mathrm{SD}=0.06$ ), were found to be significantly higher than those of the step experiment $(M=0.73, \mathrm{SD}=0.05)$, $t(118)=24.70, p<0.001, g_{s}=4.3$.

\subsection{Visual wear analysis}

Before testing, tread surface roughness was measured at $S_{\mathrm{a}}=3.3 \mu \mathrm{m}, S_{\mathrm{q}}=4.1 \mu \mathrm{m}$. After five step tests surface roughness increased to $S_{\mathrm{a}}=8.4 \mu \mathrm{m}, S_{\mathrm{q}}=11.0 \mu \mathrm{m}$, which is under half the values recorded after the five slide tests, $S_{\mathrm{a}}=20.4 \mu \mathrm{m}, S_{\mathrm{q}}=26 \mu \mathrm{m}$.

After 15 slides, the tread elements surface roughness again increased, to $S_{\mathrm{a}}=24.7 \mu \mathrm{m}, S_{\mathrm{q}}=30.1 \mu \mathrm{m}$. Through observation of the colour bars in Fig. 7, the increase in roughness with slide number is evident. It can also be seen that as slide number increases, a regular topography starts to emerge in the form of ridges. After the 15 slides in the reverse direction, the surface roughness drops again to values like those after the first five slides: $S_{\mathrm{a}}=20.5 \mu \mathrm{m}$, $S_{q}=25.4 \mu \mathrm{m}$. After these 15 slides in the reverse direction, the periodic nature of the roughness is still observable, with similar spacing between ridges $(\approx 0.4 \mathrm{~mm})$. The movement of rubber in the opposite direction had little effect on ridge spacing, which is expected as the applied normal load was constant $[27,28]$. The direction reversal altered the ridge 

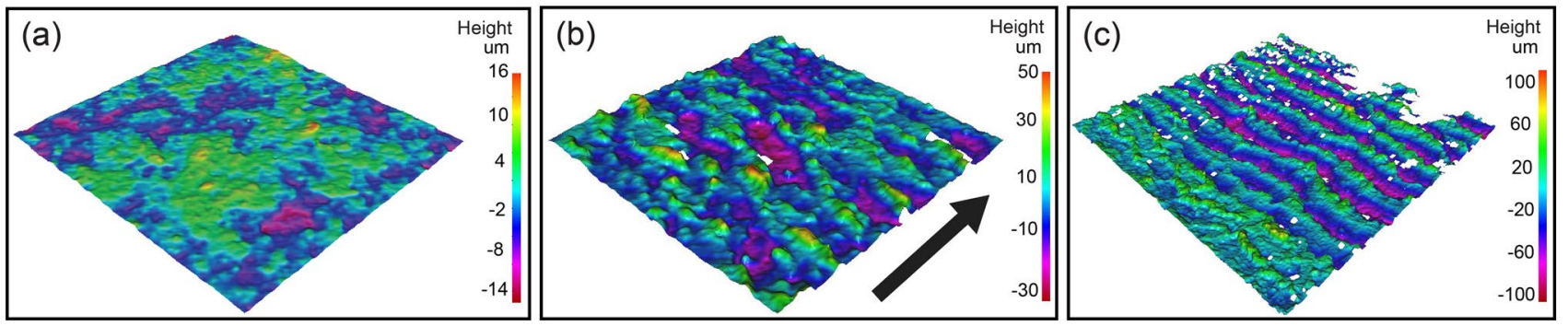

Fig. 7 Rubber surface scans taken of the short tread element used in the slide experiments. a Before any slides. b After five slides. c After 15 slides. The black arrow in $\mathrm{b}$ shows the relative sliding direction of the tread element along the hard court surface

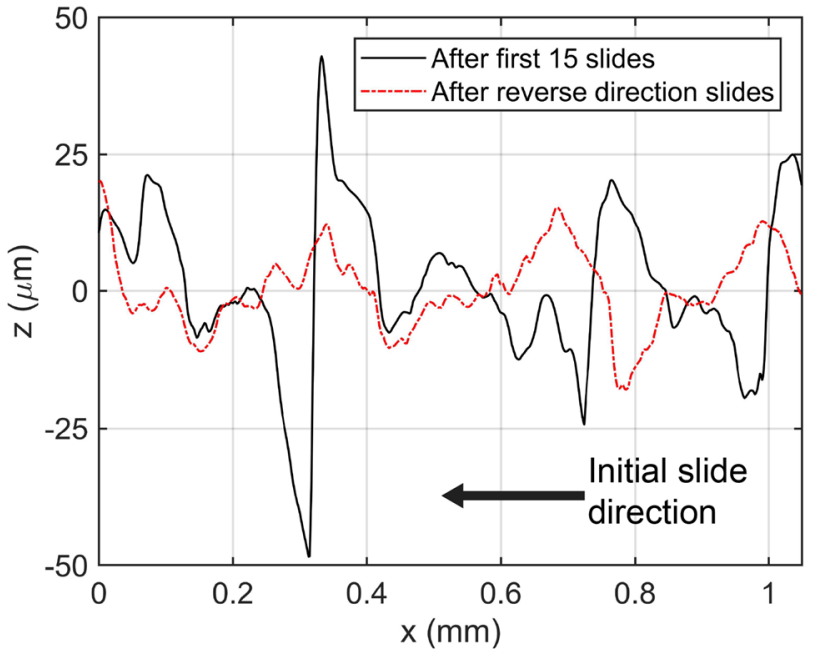

Fig. 8 2D traces of the ridges present on the surface of the short tread element used in slide experiments. The trace taken after the first 15 tests (black, solid) displays asymmetrical structures with the edge of highest gradient facing the direction of motion. After another 15 slides, but in the reverse direction (red, dashed), this directional feature is beginning to be removed. The black arrow indicates the relative sliding motion of the first 15 slides (color figure online)

profile. Before conducting tests in the reverse direction, the ridges were formed as asymmetric structures with their sharpest edge towards the oncoming surface asperities. After the additional 15 tests in the reverse direction, these peaks became more symmetrical (Fig. 8). Asymmetrical ridges on the surface of sliding rubber have been found to cause frictional differences, with the opposite sliding direction producing noticeably lower $\mu_{k}(\leq 0.2)$ [21], an observation also made in these experiments.

\section{Discussion}

$\mu_{k}$ readings were significantly higher for the slide tests than the step tests, with a large effect size of 4.3. This finding can be understood to be a combination of two primary mechanisms. The large increase in slide speed, from the step $(0.01 \mathrm{~m} / \mathrm{s})$ to the slide $(2 \mathrm{~m} / \mathrm{s})$, means the frequencies of vibration transmitted to the rubber tread elements were higher, incurring a greater hysteretic energy loss [29]. However, as is typically expected at speeds over $0.1 \mathrm{~m} / \mathrm{s}$, the frictional heat generated at the sliding interface would be sufficient to reduce the hysteresis of the rubber through thermal softening [30]. In this present case, it could be inferred that the effect of the increased perturbing frequencies of vibration on the rubber's hysteresis loss is the dominant mechanism, or that there is an additional mechanism that may also be increasing the $\mu_{k}$ during slides. This additional mechanism may be the wearing process. For rubber to experience wear, bonds must be broken within the material, requiring energy and thus increasing friction. Mass loss was almost 100 times greater during the slide tests than the step tests, making wear likely to be a component factor to the increased friction.

Another difference between step and slide results, is how, during the first 15 slides, the $\mu_{k}$ increased. It is hypothesised that this $\mu_{k}$ increase is due to the increasing size of the ridges (Fig. 7) that form on the surface during the slide tests. This hypothesis is supported by a study on rubber wear patterning which commented that friction force, though erratic, seemed to increase with an increase in ridge height [28].

In the 15 reverse direction step tests, the long tread orientation produced higher $\mu_{k}$ than the short orientation $\left(g_{s}=2\right)$. In previous studies investigating the effect of rubber block orientation on rough surface friction, the orientation with the longer shape gave lower friction $[17,20]$, the opposite to that observed here for steps. In $[17,20]$, the main reasons for the longer shape producing the lower $\mu_{k}$ were increased frictional heating at the rear of the shape, and less wear across the shorter leading edge of the long shape. In the case of the 15 reverse direction step tests, it is likely that, due to the low slide speed of steps, little difference in frictional heat is experienced between the short and long orientations. Both orientations experienced little wear $(<1 \%)$. As such, both potential reasons for long shapes producing lower friction are not applicable. The case of longer shapes of rubber

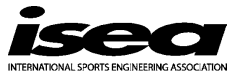




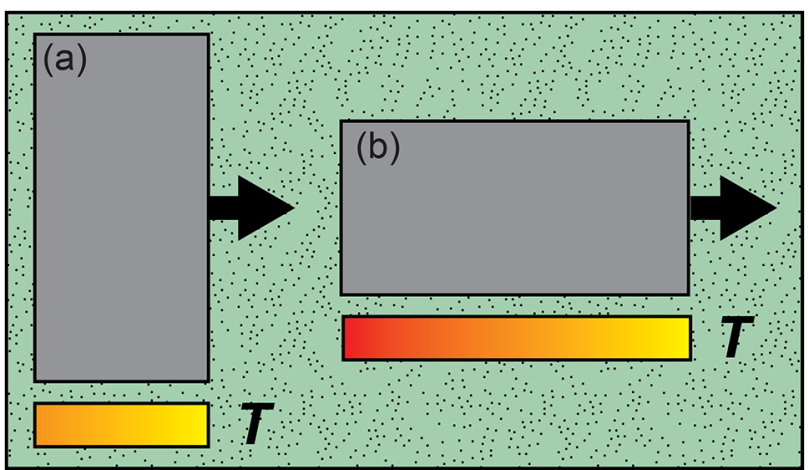

Fig. 9 How frictional heat influences shapes of rubber ( $\mathrm{T}$ indicates temperature and the arrows indicate slide direction). a A block orientated perpendicular to the slide direction. $\mathbf{b}$ A block orientated parallel to the slide direction. At slide speeds $>1 \mathrm{~mm} / \mathrm{s}$, block "a", will experience more heat, reducing its hysteresis [20]

producing higher friction has been observed in rubber friction studies on smooth surfaces [31,32]. Friction increases with shape length due to the reduced friction-induced torque experienced. Tread elements with higher second moment of area in the slide direction, produce higher contact areas and lower mean contact pressure which results in a higher friction [33]. As little wear was observed for the step tests $(<1 \%)$, differing friction-induced torque explains why the long orientation produced higher friction than the short orientation for the last 15 tests.

The effect of tread orientation on $\mu_{k}$ of slides was the opposite to that of steps. Long tread orientation produced lower $\mu_{k}$ both before and after the change of direction. Though not measured here, this was expected due to temperatures generated at the rubber-surface interface at the higher sliding speed. Frictional heat is generated by the attachment-detachment cycles that happen between contacting asperities on the surface and rubber. A surface asperity experiences more of these cycles when the shape is longer in the slide direction, making longer shapes warmer [20] (Fig. 9).

Friction tests with similar tread elements observed that short tread element orientations produced lower mean $\mu_{s}$ and $\mu_{k}$ than long orientations [14]. This matches the results observed for the step tests here, but not the slide tests. As the tests in [14] were at slide speeds between 0.15 and $0.4 \mathrm{~m} / \mathrm{s}$, they fall between the speeds tested here, and suggest the frictional heating that causes long orientated tread to have a lower friction, requires further increase in slide speed. A future study measuring tread temperature as a function of slide speed would help identify the speeds at which heating has a quantifiable effect on tread friction.

Across all experimental conditions, reversal of the slide direction reduced friction. This is thought to be the result of the topographical changes made to the surface of the tread elements during the first 15 steps or slides. These topographical changes, shown in Figs. 7 and 8, are widely observed in rubber sliding scenarios [27, 28, 34, 35]. These ridges form through the repeated abrasion of the rubber by harder surface asperities. The geometric asymmetry of these ridges means that the contact pressure will vary depending on the slide direction, with the initial sliding direction having a more uniform pressure (typically causing higher friction) than the reverse direction [21]. The change in sliding direction effectively tears these asymmetric ridges, reducing their height (from 0.9 to $0.3 \mathrm{~mm}$ ) and asymmetric geometry.

\section{Conclusions}

Using a test methodology developed previously, the friction and wear of tennis shoe tread elements was investigated. Slide experiments were found to produce higher dynamic friction than step experiments, due to both the higher frequencies transferred to the rubber increasing hysteresis, and increased wear, both of which are influenced by slide speed. No difference in static friction was observed for the change in tread orientation for step movements, though greater dynamic friction was observed for the short tread orientation during all slide tests. Both movements caused a roughening of the rubber surface, which alters the friction and, in some cases, caused frictional asymmetry. The frictional effect of rubber's changing surface topography is expected to affect the performance of step and slides over time in hard court tennis.

Acknowledgements The authors acknowledge the funding to conduct this research from the Engineering and Physical Science Research Council (EPSRC) (Grant number: EP/L01629X/1) and the International Tennis Federation (ITF). We would also like to thank Sport Group for supplying the surface and acknowledge Jamie Booth for the technical support provided.

\section{Declarations}

Conflict of interest The authors declare no potential conflicts of interest regarding the content, authorship, and the publication of this research article.

Open Access This article is licensed under a Creative Commons Attribution 4.0 International License, which permits use, sharing, adaptation, distribution and reproduction in any medium or format, as long as you give appropriate credit to the original author(s) and the source, provide a link to the Creative Commons licence, and indicate if changes were made. The images or other third party material in this article are included in the article's Creative Commons licence, unless indicated otherwise in a credit line to the material. If material is not included in the article's Creative Commons licence and your intended use is not permitted by statutory regulation or exceeds the permitted use, you will need to obtain permission directly from the copyright holder. To view a copy of this licence, visit http://creativecommons.org/licenses/by/4.0/. 


\section{References}

1. Nigg BM, Stefanyshyn DJ, Rozitis AI, Mündermann A (2009) Resultant knee joint moments for lateral movement tasks on sliding and non-sliding sport surfaces. J Sports Sci 27(5):427-435. https://doi.org/10.1080/02640410802669161

2. Luo G, Stefanyshyn D (2011) Identification of critical traction values for maximum athletic performance. Footwear Sci 3(3):127138. https://doi.org/10.1080/19424280.2011.639807

3. Worobets J, Wannop JW (2015) Influence of basketball shoe mass, outsole traction, and forefoot bending stiffness on three athletic movements. Sports Biomech 14(3):351-360. https://doi.org/10. 1080/14763141.2015.1084031

4. Worobets JT, Panizzolo F, Hung S, Wannop JW, Stefanyshyn DJ (2014) Increasing running shoe traction can enhance performance. Res J Text Appar 18(2):17-22. https://doi.org/10.1108/ RJTA-18-02-2014-B003

5. Müller C, Sterzing T, Lange J, Milani TL (2010) Comprehensive evaluation of player-surface interaction on artificial soccer turf. Sports Biomech 9(3):193-205. https://doi.org/10.1080/14763141. 2010.511679

6. Damm LC, Low D, Richardson A, Clarke J, Carre M, Dixon S (2013) The effects of surface traction characteristics on frictional demand and kinematics in tennis. Sports Biomech 12(4):389-402. https://doi.org/10.1080/14763141.2013.784799

7. Damm L, Starbuck C, Stocker N, Clarke J, Carré M, Dixon S (2014) Shoe-surface friction in tennis: influence on plantar pressure and implications for injury. Footwear Sci 6(3):155-164. https://doi.org/10.1080/19424280.2014.891659

8. Ismail SI, Nunome H, Tamura Y (2020) Does visual representation of futsal shoes outsole tread groove design resemblance its mechanical traction, dynamic human traction performance, and perceived traction during change of direction and straight sprint tasks? Footwear Sci. https://doi.org/10.1080/19424280.2020. 1825534

9. Dowling AV, Corazza S, Chaudhari AM, Andriacchi TP (2010) Shoe-surface friction influences movement strategies during a sidestep cutting task: implications for anterior cruciate ligament injury risk. Am J Sports Med 38(3):478-485. https://doi.org/10. $1177 / 0363546509348374$

10. Kovacs MS (2009) Movement for tennis: the importance of lateral training. Strength Condition J 31(4):77-85. https://doi.org/ 10.1519/SSC.0b013e3181afe806

11. Pavailler S, Horvais N (2014) Sliding allows faster repositioning during tennis specific movements on hard court. Proc Eng 72:859-864. https://doi.org/10.1016/j.proeng.2014.06.157

12. Ura D (2016) Development of a test device to measure the tribological behaviour of shoe-surface interactions in tennis. $\mathrm{PhD}$ thesis, University of Sheffield. http://etheses.whiterose.ac.uk/16882/

13. Hemler SL, Charbonneau DN, Beschorner KE (2020) Predicting hydrodynamic conditions under worn shoes using the taperedwedge solution of Reynolds equation. Tribol Int 145:106161. https://doi.org/10.1016/j.triboint.2020.106161

14. Goff JE, Ura D, Boswell L, Carré MJ (2016) Parametric study of simulated tennis shoe treads. Proc Eng 147:443-448. https://doi. org/10.1016/j.proeng.2016.06.338

15. Goff JE, Boswell L, Ura D, Kozy M, Carré MJ (2018) Critical shoe contact area ratio for sliding on a tennis hard court. Proc Instit Mech Eng Part P J Sports Eng Technol 232(2):112-121. https://doi.org/10.1177/1754337117715341

16. Ura D, Clarke J, Carré M (2013) Effect of shoe orientation on shoe-surface traction in tennis. Footwear Sci 5(sup1):S86-S87. https://doi.org/10.1080/19424280.2013.799573
17. Hale J, Lewis R, Carré MJ (2020) Rubber friction and the effect of shape. Tribol Int 141:105911. https://doi.org/10.1016/j.tribo int.2019.105911

18. Hale J, Lewis R, Carré MJ (2020) Shoe-surface tribology in hardcourt tennis. Multidiscip Digit Publ Inst Proc 49(1):90. https://doi. org/10.3390/proceedings2020049090

19. Emami A, Khaleghian S (2019) Investigation of tribological behavior of Styrene-Butadiene Rubber compound on asphalt-like surfaces. Tribol Int 136:487-495. https://doi.org/10.1016/j.tribo int.2019.04.002

20. Fortunato G, Ciaravola V, Furno A, Lorenz B, Persson BNJ (2015) General theory of frictional heating with application to rubber friction. J Phys Condens Matter 27(17):175008. https://doi.org/ 10.1088/0953-8984/27/17/175008

21. Tiwari A, Dorogin L, Steenwyk B, Warhadpande A, Motamedi M, Fortunato G, Ciaravola V, Persson BNJ (2017) Rubber friction directional asymmetry. EPL (Europhys Lett) 116(6):66002. https://doi.org/10.1209/0295-5075/116/66002

22. Starbuck C, Damm L, Clarke J, Carré M, Capel-Davis J, Miller S, Stiles V, Dixon S (2016) The influence of tennis court surfaces on player perceptions and biomechanical response. J Sports Sci 34(17):1627-1636. https://doi.org/10.1080/02640414.2015.11279 88

23. Clarke J, Carre MJ, Damm L, Dixon S (2013) The development of an apparatus to understand the traction developed at the shoesurface interface in tennis. Proc Inst Mech Eng Part P J Sports Eng Technol 227(3):149-160. https://doi.org/10.1177/1754337112 469500

24. Lakens D (2013) Calculating and reporting effect sizes to facilitate cumulative science: a practical primer for t-tests and ANOVAs. Front Psychol 4:863. https://doi.org/10.3389/fpsyg.2013.00863

25. Holm S (1979) A simple sequentially rejective multiple test procedure. Scand J Stat pp 65-70. https://www.jstor.org/stable/46157 33

26. Rice ME, Harris GT (2005) Comparing effect sizes in follow-up studies: ROC Area, Cohen's d, and r. Law Hum Behav 29(5):615. https://doi.org/10.1007/s10979-005-6832-7

27. Iwai T, Uchiyama Y, Shimosaka K, Takase K (2005) Study on the formation of periodic ridges on the rubber surface by friction and wear monitoring. Wear 259(1-6):669-675. https://doi.org/10. 1016/j.wear.2005.01.012

28. Uchiyama Y, Ishino Y (1992) Pattern abrasion mechanism of rubber. Wear 158(1-2):141-155. https://doi.org/10.1016/00431648(92)90035-7

29. Persson BN (2001) Theory of rubber friction and contact mechanics. J Chem Phys 115(8):3840-3861. https://doi.org/10.1063/1. 1388626

30. Persson BNJ (2014) Role of frictional heating in rubber friction. Tribol Lett 56(1):77-92. https://doi.org/10.1007/ s11249-014-0386-0

31. Maegawa S, Itoigawa F, Nakamura T (2016) A role of frictioninduced torque in sliding friction of rubber materials. Tribol Int 93:182-189. https://doi.org/10.1016/j.triboint.2015.08.030

32. Moriyasu K, Nishiwaki T, Shibata K, Yamaguchi T, Hokkirigawa K (2019) Friction control of a resin foam/rubber laminated block material. Tribol Int 136:548-555. https://doi.org/10.1016/j.tribo int.2019.04.024

33. Fortunato G, Ciaravola V, Furno A, Scaraggi M, Lorenz B, Persson BN (2017) Dependency of rubber friction on normal force or load: theory and experiment. Tire Sci Technol 45(1):25-54. https://doi.org/10.2346/tire.17.450103

34. Wang Z, Hu S, Miao Z, Ma L (2018) Application of multifractal spectrum calculation program in rubber wear under high temperature. Wireless Pers Commun 103(1):1-9. https://doi.org/10.1007/ s11277-018-5419-9 
35. Hakami F, Pramanik A, Ridgway N, Basak AK (2017) Developments of rubber material wear in conveyer belt system. Tribol Int 111:148-158. https://doi.org/10.1016/j.triboint.2017.03.010
Publisher's Note Springer Nature remains neutral with regard to jurisdictional claims in published maps and institutional affiliations. 